\title{
Bystander immunotherapy as a strategy to control allergen-driven airway inflammation
}

\author{
S Navarro ${ }^{1,3}$, A Lazzari ${ }^{1}$, A Kanda ${ }^{2}$, S Fleury ${ }^{2}$, D Dombrowicz ${ }^{2}$, N Glaichenhaus ${ }^{1}$ and V Julia ${ }^{1}$
}

\begin{abstract}
Allergic asthma is a chronic inflammatory disease characterized by airway hyperresponsiveness (AHR), lung infiltration of Th2 cells, and high levels of IgE. To date, allergen-specific immunotherapy (SIT) is the only treatment that effectively alleviates clinical symptoms and has a long-term effect after termination. Unfortunately, SIT is unsuitable for plurisensitized patients, and highly immunogenic allergens cannot be used. To overcome these hurdles, we sought to induce regulatory $\mathrm{CD} 4{ }^{+}$Tcells $\left(\mathrm{T}_{\text {reg }}\right)$ specific to an exogenous antigen that could be later activated as needed in vivo to control allergic responses. We have established an experimental approach in which mice tolerized to ovalbumin (OVA) were sensitized to the Leishmania homolog of receptors for activated c kinase (LACK) antigen, and subsequently challenged with aerosols of LACK alone or LACK and OVA together. Upon OVA administration, AHR and allergic airway responses were strongly reduced. OVA-induced suppression was mediated by CD25 ${ }^{+} \mathbf{T}_{\text {reg, }}$, required CTLA-4 and ICOS signaling and resulted in decreased numbers of migrating airway dendritic cells leading to a strong impairment in the proliferation of allergen-specific Th2 cells. Therefore, inducing $T_{\text {reg }}$ specific to a therapeutic antigen that could be further activated in vivo may represent a safe and novel curative approach for allergic asthma.
\end{abstract}

\section{INTRODUCTION}

Allergic diseases affect up to $30 \%$ of the population and their prevalence has steadily increased in recent decades. Among allergic diseases, asthma is a chronic inflammation of the lungs caused by an inappropriate immune response to a single or multiple airborne allergens. This pathology has a substantial economic burden for which the only targeted method of treatment is allergen-specific immunotherapy (SIT). SIT involves the administration by either subcutaneous injection or mucosal application of increasing doses of the allergen to which the patient is allergic. Unfortunately, this approach is ineffective for treating multi-sensitized patients, and despite recent clinical studies, numerous allergens are too immunogenic to be used in desensitization protocols. ${ }^{1}$ SIT induces a state of peripheral tolerance characterized mainly by the generation of allergenspecific regulatory $\mathrm{T}$ cells $\left(\mathrm{T}_{\text {reg }}\right)$, along with the suppression of effector cell proliferation and cytokine production against the targeted allergen. ${ }^{2,3}$ Interleukin (IL)-10 and/or TGF- $\beta$ producing $\mathrm{T}_{\text {reg }}$ are the key factors for specific immunotherapy in humans. ${ }^{4-6}$ It has been shown that treating naive (non-sensitized) mice with ovalbumin (OVA) aerosols results in the development of OVA-specific $\mathrm{T}_{\text {reg }}$ and IgE unresponsiveness upon subsequent sensitization and challenge with OVA. ${ }^{7,8}$ Akbari et al. ${ }^{8}$ have shown that lung draining lymph node (LN) dendritic cells (DCs) are able to create a local pro-regulatory environment by transiently producing IL-10 following a first contact with an inhaled antigen $(\mathrm{Ag})$. These phenotypically mature DC induce the development of $\mathrm{T}_{\text {reg, }}$, which in turn produces IL-10.9 Respiratory tolerance can be achieved with only three intranasal (IN) administrations of Ag, which are sufficient to protect against airway hyperresponsiveness (AHR) and allergic inflammation upon further Ag sensitization and challenge. ${ }^{10}$ TGF- $\beta$ expressing $\mathrm{T}_{\text {reg }}$ also have a role in tolerance induction to inhaled Ags. ${ }^{6,11}$

In fact, SIT not only has been shown to alter the development of new sensitizations, but it has also been suggested that tolerance generated by SIT is not solely limited to the targeted allergen and also confers extended protection against other allergens. ${ }^{12,13}$ This non-specific and beneficial action of SIT could be explained by the activation of bystander $\mathrm{T}_{\text {reg. }}$.

\footnotetext{
${ }^{1}$ IPMC, CNRS UMR7275, INSERM U1080 Université de Nice-Sophia Antipolis, Valbonne, France and ${ }^{2}$ Institut Pasteur de Lille, INSERM U1011, Université de Lille 2, Lille, France. Correspondence: S Navarro (severine.navarro@jcu.edu.au) or V Julia (vjulia@unice.fr)

${ }^{3}$ Present address: Australian Institute of Tropical Health and Medicine, CBMDT, James Cook University, E4 McGregor Road, Smithfield, QLD 4878, Australia
} 
Bystander immunosuppression was first described by Bullock et al. ${ }^{14}$ as a process in which Ag-specific $\mathrm{T}_{\text {reg }}$ inhibit $\mathrm{T}$ effector cell responses directed to both the target $\mathrm{Ag}$ and to a colocalized third-party Ag. However, it was originally believed that in order for suppression to occur, the tolerogen and the Ag were required to be physically linked, i.e., presented by the same Ag-presenting cell (APC), at which point the terms linked suppression or linked recognition were coined. It was later shown that this state of induced tolerance was self-perpetuating and long lasting, and moreover, the tolerogen and the thirdparty Ag only needed to be in the vicinity of one another. ${ }^{15-18} \mathrm{In}$ the field of oral tolerance, the term bystander suppression was introduced to describe inhibition of a T-cell memory response as a result of a regulatory response generated to an unrelated but colocalized tolerogen. ${ }^{16,19,20}$ In bystander suppression, the tolerogen and third-party Ag do not need to be presented by the same APC. Admittedly, while soluble mediators are critical to induce suppression of the response directed to the third-party Ag, contact-based cell interactions are not excluded ${ }^{19,21-23}$ and have been recently demonstrated during graft tolerance. ${ }^{24}$

In this study, we have investigated whether $\mathrm{T}_{\text {reg }}$ specific for a third-party therapeutic Ag could control allergic immune responses and lung inflammation in mice. More specifically, we sought to demonstrate that therapeutic Ag-specific $\mathrm{T}_{\text {reg }}$ could be recruited into the airway mucosa as needed during acute inflammatory bursts, and alter the natural development of allergic disease by modifying the microenvironment. To this aim, the Leishmania homolog of receptors for activated c kinase (LACK) Ag was used as an allergen model as described previously. ${ }^{25,26}$ Briefly, mice were sensitized to LACK, tolerized to OVA through three IN administrations as described previously, ${ }^{8}$ and challenged with aerosols of LACK alone or with an additional OVA aerosol treatment to activate/recruit previously generated OVA-specific $\mathrm{T}_{\text {reg. }}$.

\section{RESULTS}

\section{Exposure to OVA aerosols inhibits LACK-induced allergic asthma in OVA-tolerized mice}

To determine whether $\mathrm{T}_{\text {reg }}$ specific for a third-party Ag could control allergic airway inflammation, mice were sensitized to LACK, tolerized to OVA through IN administrations, a protocol reported to induce respiratory tolerance via the induction of OVA-specific Treg, ${ }^{9,10}$ and tested for their ability to develop unresponsiveness to OVA upon further OVA immunization and challenge. When compared with phosphate-buffered saline (PBS)-treated mice, LACK-sensitized mice treated with OVA exhibited reduced AHR and airway allergic inflammation upon sensitization and challenge to OVA (Supplementary Figure 1 online). In addition, OVA-treated mice also exhibited decreased OVA-specific IgE, further confirming that our treatment induced a state of tolerance to OVA (Supplementary Figure 1). To investigate whether tolerance to OVA could improve asthma-related symptoms in mice sensitized and challenged to LACK, we sensitized mice to LACK and tolerized them to OVA and further challenged them with LACK aerosols alone (control) or both LACK and OVA to activate and recruit OVA-specific $\mathrm{T}_{\text {reg }}$ to the airways (Figure 1a). When compared with the control group, mice treated with OVA aerosols showed decreased AHR (Figure 1b), reduced numbers of total cells, eosinophils, and lymphocytes in the bronchoalveolar lavage fluids (BALFs) (Figure 1c), and more specifically a reduced number of airway-infiltrating $\mathrm{CD} 4{ }^{+} \mathrm{T}$ cells expressing the Th2- marker T1/ST2 (IL-33Ra) (Figure 1d). Concentrations of IL-4, IL-5, and IL-13 in the BALF were also decreased upon exposure to OVA during LACK challenges, while interferon (IFN)- $\gamma$ levels remained low and comparable in both groups (Figure 1e). Interestingly, intracellular staining showed that OVA aerosols significantly decrease both the frequency and the number of IL-4, and IL-5-secreting LACK-specific CD4 ${ }^{+} \mathrm{T}$ cells in comparison with mice that received LACK only aerosols (Figure 1f). However, in our particular experimental settings, levels of LACK-specific IgE and IgG1 were not affected by OVA treatment (Figure 1g). Since therapeutic administration of OVA was given during the LACK challenge phase, it was possible that the decreased amplitude of LACK-specific responses could be due to an artifact related to a suboptimal availability of LACK-loaded APCs. For this reason, we sensitized mice to LACK, omitted the OVA IN administrations, and challenged them with either LACK or both LACK/OVA aerosols (Supplementary Figure 2). Both groups exhibited similar AHR and BALF cellular infiltration, providing further evidence that the decrease in inflammation observed in the LACK/OVA-treated group was not due to diminished LACK-derived Ag presentation but rather to the induction of suppressive mechanisms (Supplementary Figure 2).

To confirm our observations with a human relevant allergen, mice were tolerized to OVA, exposed to a series of ragweed (Ambrosia artemisiifolia) IN injections, and later administered an OVA IN analeptic (Figure 2a). Similar to our previous results, mice treated with OVA at the later phase of ragweedinduced inflammation showed decreased AHR (Figure 2b), reduced total numbers of cells, eosinophils, and lymphocytes in BALF (Figure 2c), and a significant reduction in both the number and frequency of $\mathrm{T} 1 / \mathrm{ST} 2{ }^{+} \mathrm{CD} 4{ }^{+} \mathrm{T}$ cells when compared with the control group, suggesting that ragweed-specific Th2 responses have been controlled (Figure 2d). Likewise, BALF levels of IL-4 and IL-13 were also reduced upon later treatment with OVA, while IFN- $\gamma$ levels remained low and comparable in both groups (Figure 2e). Altogether, our results suggested that OVA-induced tolerance could inhibit AHR, allergic airway inflammation and allergen-specific Th2 immune responses directed to another unrelated Ags.

\section{Inhibition of LACK-induced airway inflammation in OVA-tolerized mice is mediated by OVA-specific $\mathrm{CD25}^{+} \mathrm{T}_{\text {reg }}$}

Previous reports have shown that, in the absence of reporter mice, regulatory cells could be purified from the spleen of tolerized mice. ${ }^{6,26,27}$ To investigate whether OVA-specific $T_{\text {reg }}$ were responsible for the suppression of LACK-induced airway inflammation, and whether this protection was Ag specific, 
a

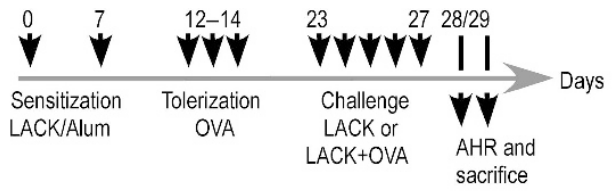

b
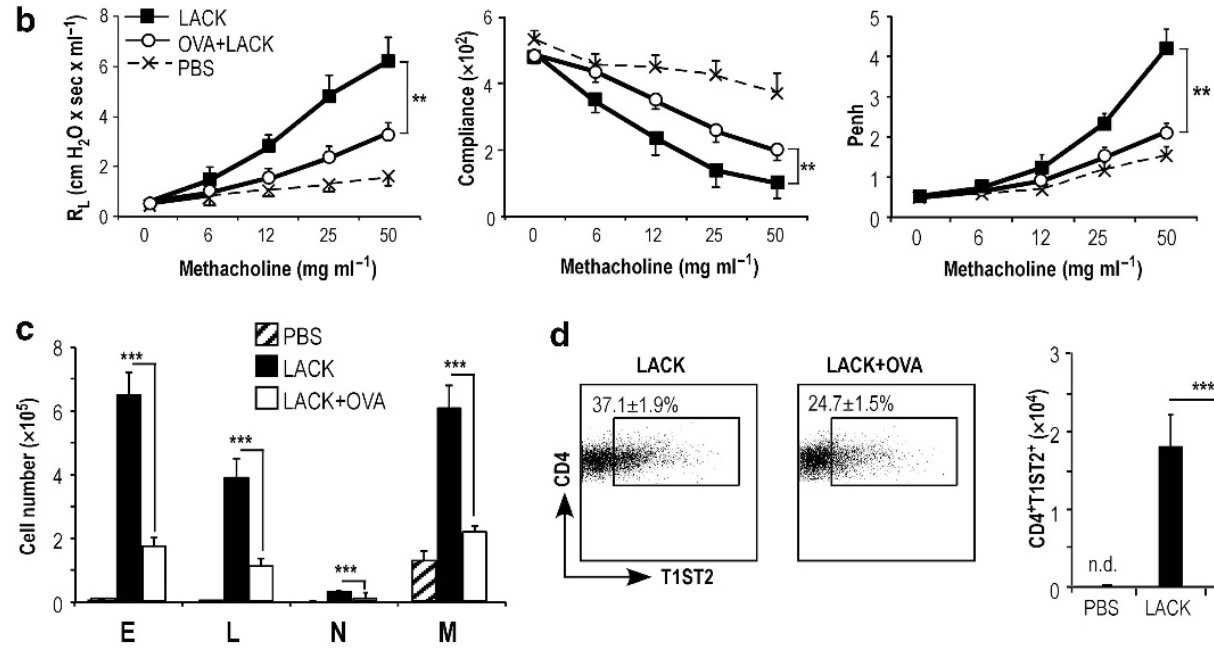

d
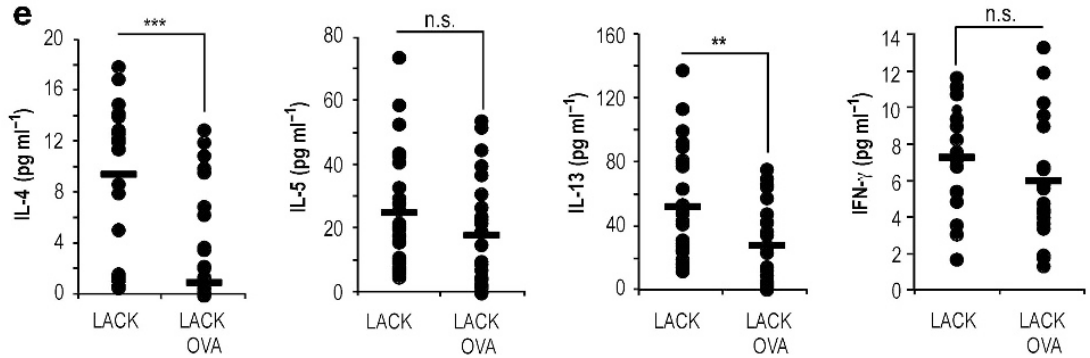

f
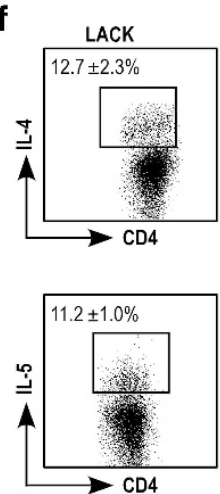

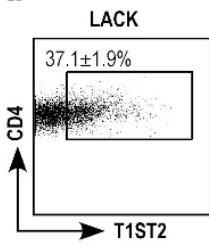

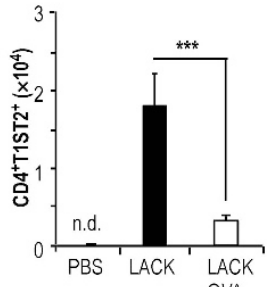

OVA
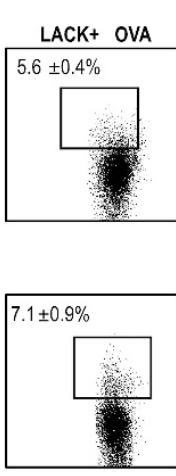
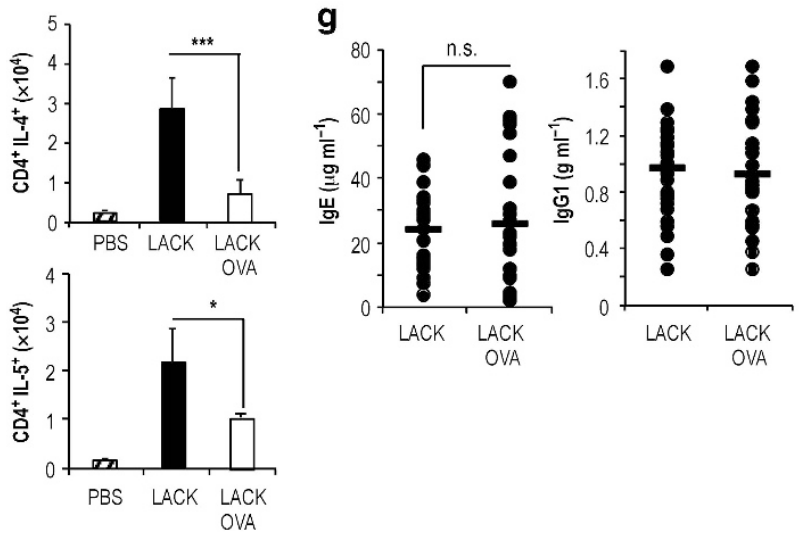

Figure 1 Airway hyperresponsiveness (AHR), airway inflammation, and cytokine levels in ovalbumin (OVA)-tolerized mice exposed to both OVA and Leishmania homolog of receptors for activated c kinase (LACK) aerosols. (a) Experimental protocol. Mice were sensitized with two intraperitoneal injections of LACK in Alum, treated with three intranasal (IN) injections of OVA, and challenged daily for 5 days with LACK aerosols or LACK/OVA aerosols. Mice were analyzed 1 and 2 days after the last aerosol. (b) AHR. Whole body plethysmography (right), and dynamic lung resistance and compliance (left) were monitored in mice exposed to LACK aerosols (filled squares), LACK/OVA aerosols (empty circles), or phosphate-buffered saline (PBS) (crosses, dashed line). (c) Number and phenotype of bronchoalveolar lavage fluid (BALF) cells. BALF cells were counted and analyzed by fluorescence in situ hybridization (FACS) in mice exposed to PBS (dashed bars), LACK (black bars), or LACK/OVA aerosols (empty bars). Data show the number of eosinophils (E), neutrophils $(N)$, lymphocytes (L), and macrophages (M). (d) Frequency and number of Th2 cells in the airways. BALF cells were stained with anti-CD4, CD3, and T1/ST2 mAbs and analyzed by FACS. Data show representative FACS profiles, numbers indicate the mean frequency \pm s.e.m. and histograms show the absolute numbers of T1ST2 ${ }^{+} \mathrm{CD} 4{ }^{+} \mathrm{T}$ cells for the indicated groups. (e) Cytokine levels in BALF. Mice were analyzed for interleukin (IL)-4, IL-5, IL-13, and interferon (IFN)- $\gamma$ by cytometric bead array (CBA). (f) Cytokine secretion by lung CD4 ${ }^{+}$T cells. IL-4 and IL5-secreting CD4 ${ }^{+}$T cells were assessed by FACS after in vitro stimulation with LACK protein $\left(0.1 \mathrm{mg} \mathrm{ml}^{-1}\right)$, anti-CD28 $\left(1 \mu \mathrm{g} \mathrm{ml}{ }^{-1}\right)$, and brefeldin A $\left(5 \mu \mathrm{g} \mathrm{ml}^{-1}\right)$. Data show representative FACS profiles, numbers indicate the mean frequency \pm s.e.m. and histograms show the absolute numbers for the indicated groups. (g) Immunoglobulins. Levels of serum LACK-specific IgE and IgG1 were assessed in mice upon challenge with LACK or LACK/OVA aerosols. All data show either individual mice with bar indicating the mean, with $n=6$ mice per group pooled from four different experiments. n.s., nonsignificant, ${ }^{*} P<0.05,{ }^{* *} P<0.01,{ }^{* * *} P<0.0001$. 

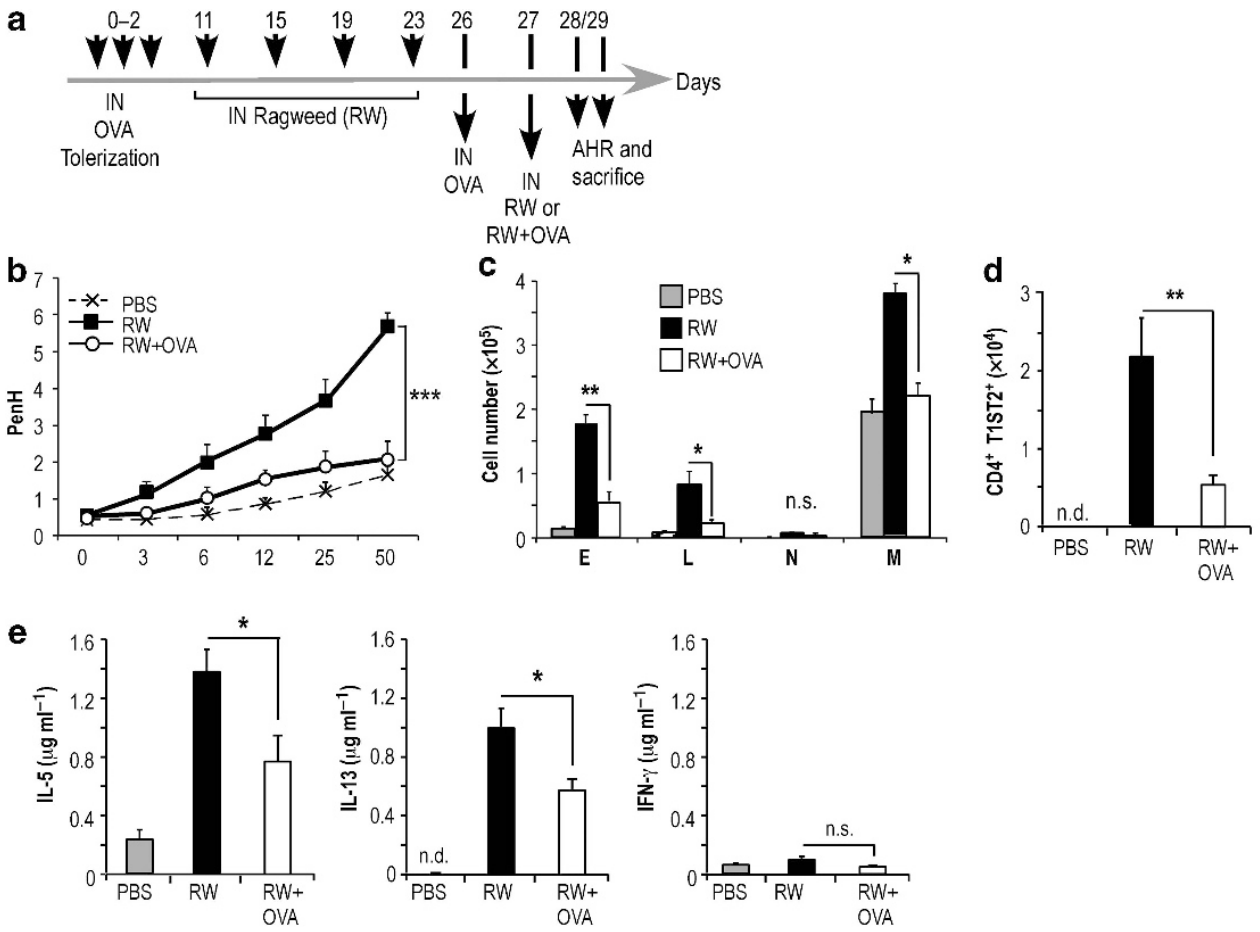

Figure 2 Airway hyperresponsiveness (AHR), airway inflammation, and cytokine levels in ragweed-sensitized, ovalbumin (OVA)-tolerized mice upon ragweed challenge. (a) Experimental protocol. Mice were treated with three intranasal (IN) injections of OVA, and four IN injections of ragweed. Mice were then challenged with either ragweed or ragweed/OVA, and analyzed 1 and 2 days after the last IN injection. (b) AHR. Whole body plethysmography in mice exposed to ragweed (filled squares), ragweed/OVA (empty circles), or phosphate-buffered saline (PBS) (crosses). (c) Number and phenotype of bronchoalveolar lavage fluid (BALF) cells. BALF cells were analyzed by fluorescence in situ hybridization (FACS) in mice exposed to ragweed only (black bars), to both ragweed and OVA aerosols (empty bars) or to PBS (gray bars). Eosinophils, E; neutrophils, N; lymphocytes, L; and macrophages, M. (d) Frequency and number of Th2 cells in the airways. BALF cells were stained with CD4 and T1/ST2 mAbs and analyzed by FACS. (e) Cytokine levels in lung cells. Interleukin (IL)-4, IL-5, and interferon (IFN)- $\gamma$ levels were assessed by ELISA after in vitro stimulation with Leishmania homolog of receptors for activated $\mathrm{c}$ kinase (LACK) protein $\left(0.1 \mathrm{mg} \mathrm{ml}^{-1}\right)$, anti-CD28 $\left(1 \mu \mathrm{g} \mathrm{ml}^{-1}\right)$ and brefeldin A $\left(5 \mu \mathrm{g} \mathrm{ml}^{-1}\right)$. Data are expressed as mean \pm s.e.m. of two experiments with $n=8$ mice per group. n.s., non-significant; ${ }^{\star} P<0.05 ;{ }^{\star \star} P<0.01$.

total $\mathrm{CD} 4^{+} \mathrm{T}$ cells were purified from the spleen of mice previously tolerized to OVA, or bovine serum albumin (BSA), or mock injection (PBS). Cells were injected into LACKsensitized recipient mice that were further treated with OVA aerosols alongside LACK challenges (Figure 3a). In contrast to the mice injected with $\mathrm{CD} 4{ }^{+} \mathrm{T}$ cells purified from BSA-tolerized or PBS-treated donors, mice injected with CD4 ${ }^{+}$ $\mathrm{T}$ cells from OVA-tolerized mice exhibited decreased AHR (Figure $3 \mathbf{b}$ ), reduced numbers of total cells, eosinophils, and lymphocytes (Figure 3c) as well as $\mathrm{T} 1 / \mathrm{ST} 2{ }^{+} \mathrm{CD} 4^{+} \mathrm{T}$ cells in BALF (Figure 3d), and reduced numbers of lung IL-4- and IL-5-producing LACK-specific CD4 ${ }^{+} \mathrm{T}$ cells (Figure 3e).

Interestingly, $\mathrm{CD} 4^{+} \mathrm{T}$ cells from OVA-tolerized mice were unable to transfer protection when depleted from the CD25expressing cell subpopulation (Figure $\mathbf{3} \mathbf{f}-\mathbf{i}$ ). However, adoptive transfer of purified $\mathrm{CD} 25^{+} \mathrm{CD} 4{ }^{+} \mathrm{T}$ cells from OVA-tolerized mice provided similar levels of protection to that of the whole CD4 population (Figure 3f-i). Taken together, these results suggest that not only does the inhibition of LACK-induced airway inflammation rely on the activation of CD25-expressing $\mathrm{T}_{\text {reg }}$, but also that in order for these cells to suppress LACKinduced inflammatory processes, they need to be reactivated and/or recruited with their Ag of specificity, i.e., OVA.

\section{OVA-T $\mathrm{T}_{\text {reg }}$ depend on CTLA-4 and ICOS to control LACK-induced asthma}

It is well documented that $\mathrm{T}_{\text {reg }}$ mediate suppression through various mechanisms including the secretion of inhibitory cytokines, the induction of cytolysis, metabolic disruption, the inhibition of Ag presentation by DCs via CTLA-4-dependent mechanisms ${ }^{28}$ and ICOS-ICOS-ligand interactions. ${ }^{29}$ Consequently, we first sought to determine the role of CTLA-4 and ICOS in the inhibition of LACK-induced inflammation in our model. To this aim, LACK-sensitized OVA-tolerized mice were treated with CTLA-4, ICOS, blocking mAbs, or isotype control, during LACK/OVA challenge (Figure 4a). Interestingly, inhibition of the $\mathrm{T}_{\text {reg }}$ activation marker CTLA-4 restored AHR, airway cellular infiltration of eosinophils, lymphocytes, and $\mathrm{T} 1 / \mathrm{ST} 2^{+}$Th2 cells, along with the number of lung IL-4- and IL-5-producing LACK-specific $\mathrm{CD}^{+}{ }^{+} \mathrm{T}$ cells (Figure 4b-d). Similar results were obtained by blocking ICOS/ICOSL signaling as shown by the restoration of AHR and comparable airway infiltration of eosinophils and lymphocytes to the LACK challenged group (Figure $\mathbf{4 f}, \mathbf{g}$ ). Taken together, our results demonstrate that OVA-specific $\mathrm{T}_{\text {reg }}$ control LACKinduced AHR and allergic airway inflammation in a CTLA-4 and ICOS-dependent mechanism. 


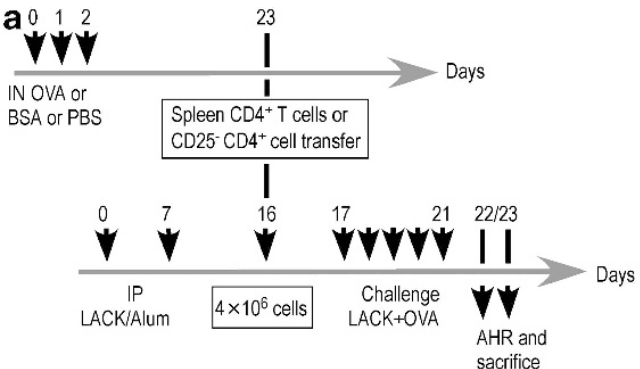

b
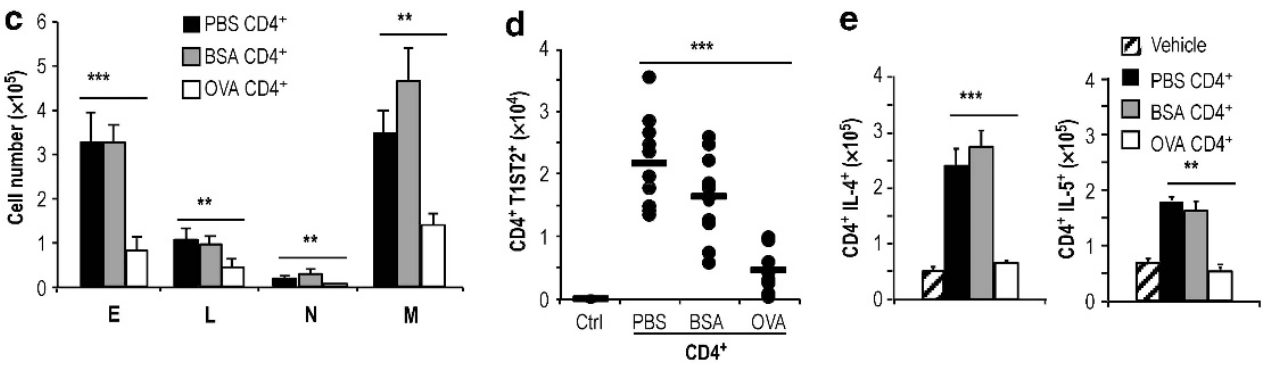
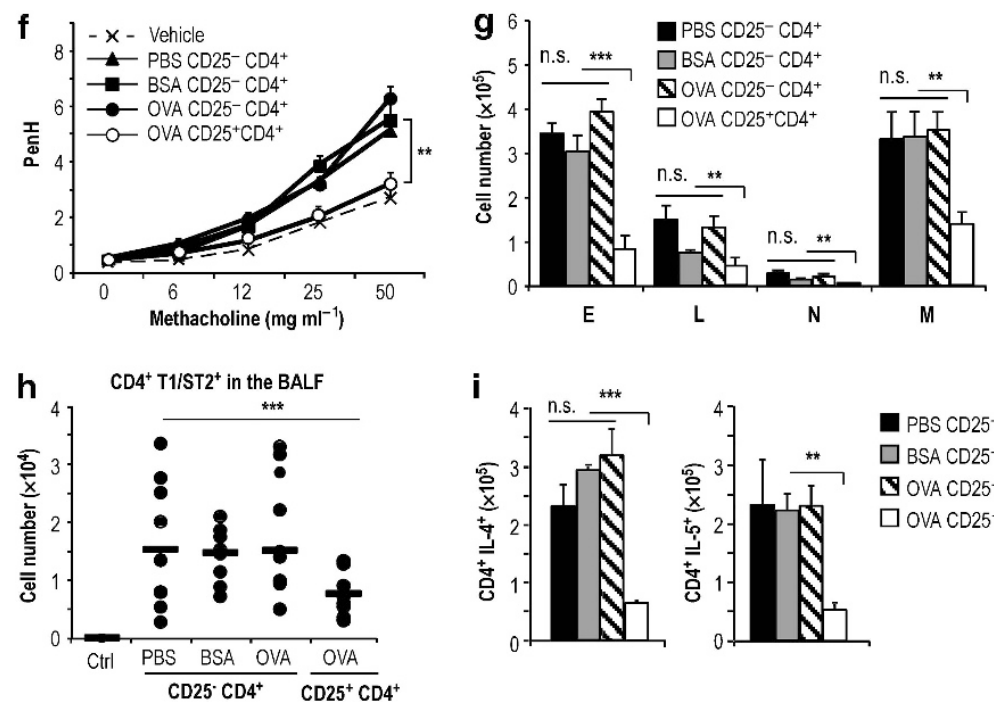

PBS CD25-CD4+

$\square \mathrm{BSACD25^{- } \mathrm { CD } 4 ^ { + }}$

$\triangle$ OVA CD25- ${ }^{-} 4^{+}$

$\square$ OVA CD25+CD4+

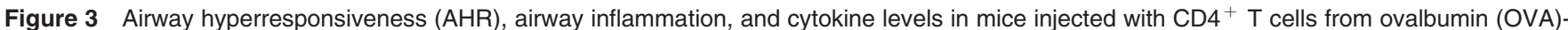
tolerized mice. (a) Experimental protocol. Mice were sensitized with two intraperitoneal (IP) injections of Leishmania homolog of receptors for activated c kinase (LACK) in Alum, and injected 9 days later with $4 \times 10^{6} \mathrm{CD} 4^{+}$T cells $(\mathbf{a}-\mathbf{e})$, or $4 \times 10^{6} \mathrm{CD} 25^{-} \mathrm{CD}^{+} \mathrm{T}$ cells $(\mathbf{f}-\mathbf{i})$ or $1.5 \times 10^{6} \mathrm{CD} 25^{+} \mathrm{CD} 4^{+} \mathrm{T}$ cells $(\mathbf{f}-\mathbf{i})$ prepared from the spleen of mice exposed to OVA, BSA, or phosphate-buffered saline (PBS). Sensitized mice were then challenged with LACK/OVA aerosols for 5 days and analyzed 1 and 2 days after the last aerosol. (b, f) AHR. Whole body plethysmography was monitored in the indicated mice challenged to LACK/OVA aerosols in response to increased doses of inhaled methacholine. Control mice (vehicle) were sensitized with LACK, nontransferred and challenged with PBS. (c, g) Number and phenotype of bronchoalveolar lavage fluid (BALF) cells. BALF cells were analyzed by fluorescence in situ hybridization (FACS) for the number of eosinophils (E), neutrophils (N), lymphocytes (L), and macrophages (M). (d, h) Frequency and number of Th2 cells in the airways. BALF cells were stained with anti-CD3, -CD4 and T1/ST2 mAbs and analyzed by FACS. (e, i) Cytokine secretion by lung $\mathrm{CD} 4^{+} \mathrm{T}$ cells. Interleukin (IL)-4 and IL-5-secreting CD4 ${ }^{+} \mathrm{T}$ cells were assessed by FACS after in vitro stimulation with $\mathrm{LACK}_{\text {protein }}\left(0.1 \mathrm{mg} \mathrm{ml}^{-1}\right)$, anti-CD28 $\left(1 \mu \mathrm{g} \mathrm{ml}^{-1}\right)$, and brefeldin $\mathrm{A}\left(5 \mu \mathrm{g} \mathrm{ml}^{-1}\right)$. Data show numbers of IL-4 and IL-5-secreting CD4 ${ }^{+} \mathrm{T}$ cells in lungs. All data show either individual mice or are expressed as mean \pm s.e.m., with $n=5$ mice per group pooled from two experiments. $P$-values have been calculated by comparing OVAtolerized mice with BSA-tolerized mice, n.s., non-significant; ${ }^{*} P<0.05,{ }^{* *} P<0.01,{ }^{* * *} P<0.0001$.

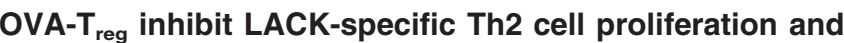 subsequent airway inflammation}

To further understand the molecular mechanisms underpinning OVA-induced protection in this system, and more particularly the effects of OVA- $\mathrm{T}_{\text {reg }}$ on LACK-specific responses, we sought to investigate the fate of LACK-specific Th2 effector cells. To this end, we modified our disease model and generated in vitro LACK-specific Th2 cells from Thy1.1 expressing LACK WT15 TCR transgenic $\mathrm{RAG}^{-1-}$ mice. As described previously, $\mathrm{CD} 4^{+} \mathrm{T}$ cells from the spleen of naïve WT15 mice were differentiated under Th2 polarizing conditions (Supplementary Figure 3), ${ }^{25,30}$ subsequently labeled with carboxyfluorescein succinimidyl ester (CFSE), and injected into OVA- or BSA-tolerized recipients before receiving a single 
a
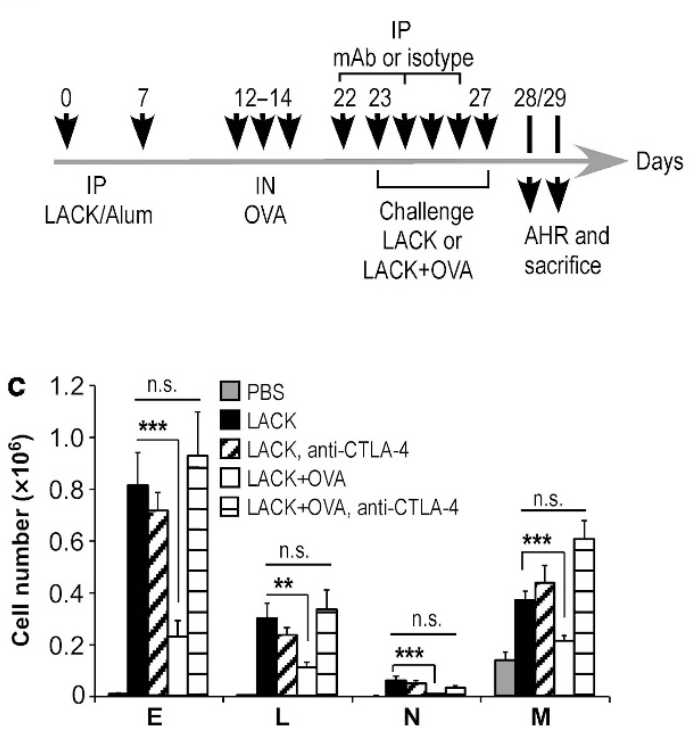

b

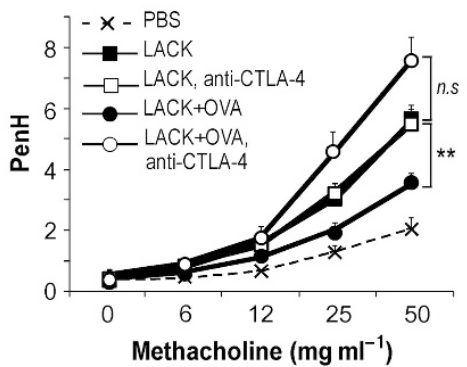

d
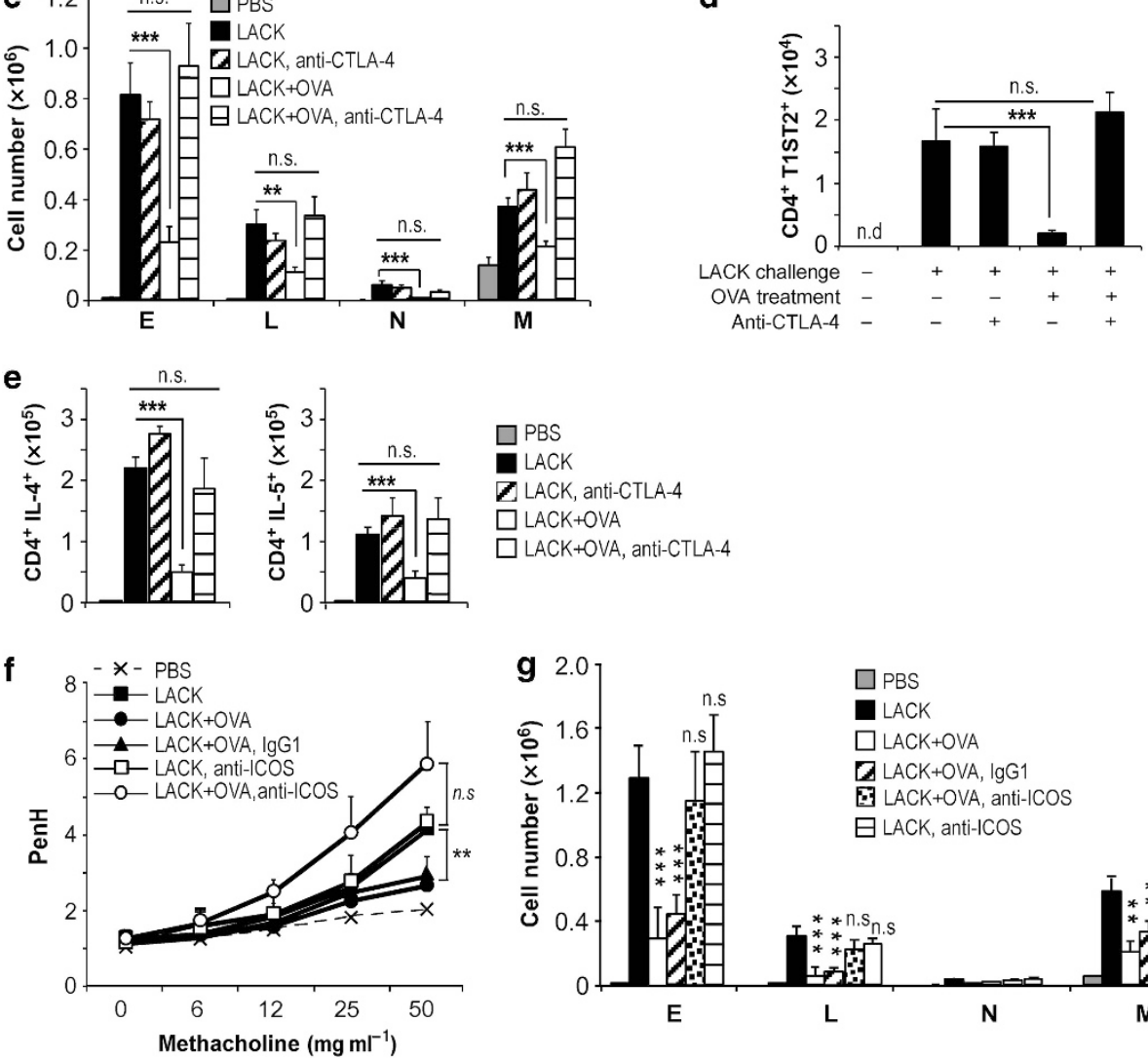

日 LACK, anti-ICOS

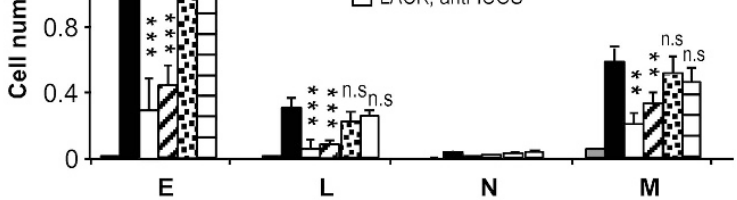

Figure 4 Airway hyperresponsiveness (AHR) and airway inflammation in mice treated with anti-CTLA-4 or anti-ICOS. (a) Experimental protocol. Mice were sensitized with two intraperitoneal (IP) injections of Leishmania homolog of receptors for activated c kinase (LACK) in Alum, treated with three intranasal (IN) injections of ovalbumin (OVA), treated or not with anti- CTLA-4 mAb, -ICOS, or IgG1 isotype mAb at the indicated time, and challenged daily for 5 days with LACK or LACK/OVA aerosols. Mice were analyzed 1 and 2 days after the last aerosol. (b, f) AHR. Whole body plethysmography in response to increasing doses of inhaled methacholine in the indicated groups of mice. (c, g) Number and phenotype of bronchoalveolar lavage fluid (BALF) cells. BALF cells were analyzed by fluorescence in situ hybridization (FACS) in the indicated groups of mice. Eosinophils, E; neutrophils, N; lymphocytes, L; and macrophages, M. (d) Number of Th2 cells in the airways. BALF cells were stained with anti-CD3, -CD4 and T1/ST2 mAbs and analyzed by FACS. (e) Interleukin (IL)-4 and IL-5-secreting CD4 ${ }^{+}$T cells were assessed by FACS after in vitro stimulation with LACK protein $\left(0.1 \mathrm{mg} \mathrm{ml}^{-1}\right)$, anti-CD28 $\left(1 \mu \mathrm{g} \mathrm{ml}^{-1}\right)$, and brefeldin $\mathrm{A}\left(5 \mu \mathrm{g} \mathrm{ml}^{-1}\right)$. Data are expressed as mean \pm s.e.m. of three experiments with $n=6 \mathrm{mice}$ per group. Experimental groups were compared with untreated LACK-challenged mice. n.s., non-significant; ${ }^{*} P<0.05 ;{ }^{* *} P<0.01 ;{ }^{* * *} P<0.0001$.

LACK + OVA IN challenge (Figure 5a). In this system, mice injected with LACK-specific Th2 cells that received an IN challenge displayed comparable inflammatory responses to the mice sensitized with LACK/Alum and challenged with aerosols used previously (Figure $\mathbf{5 b}-\mathbf{d}$ ). When compared with the BSAtolerized group, mice treated with OVA IN and injected with LACK-specific Th2 cells exhibited decreased AHR (Figure 5b), and reduced numbers of eosinophils and lymphocytes in the BALF (Figure 5c). Interestingly, while no difference was observed in the blood, both the frequency and the number of donor LACK-specific Th2 cells were significantly reduced in the BALF, lung and mediastinal LN (MedLN) of OVA-tolerized mice when compared with BSA-tolerized mice (Figure 5d). CFSE dilution profiles revealed that LACK-specific Th2 cells had undergone more divisions in BSA-tolerized mice than in OVA-tolerized mice (Figure 5e), further suggesting that OVA$\mathrm{T}_{\text {reg }}$ inhibited LACK-specific Th2 cell proliferation. To address the ability of APCs to present LACK at the time of the challenge, 
a
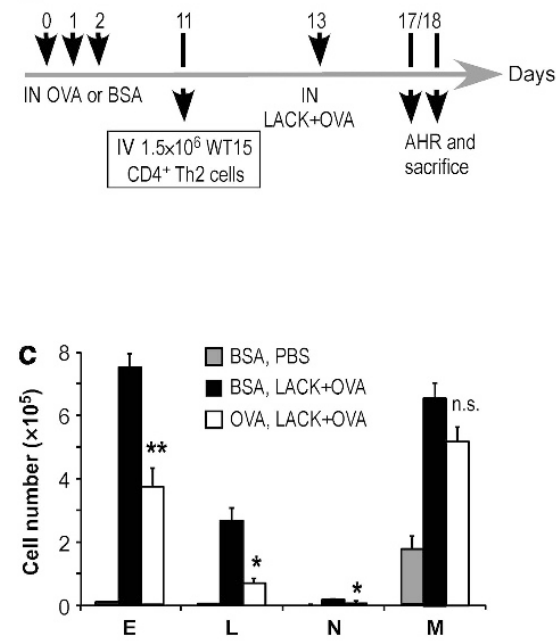

b 5 [ 1 --X- BSA IN, PBS

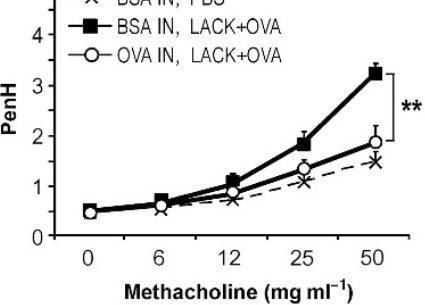

d

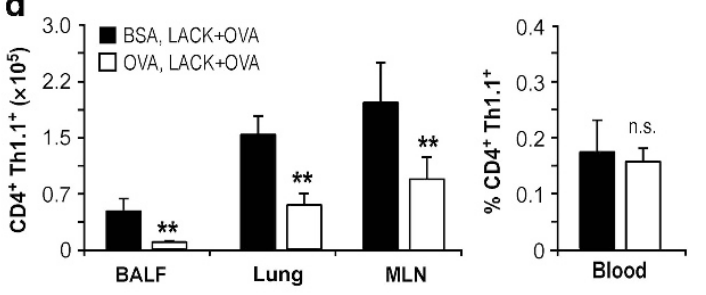

e

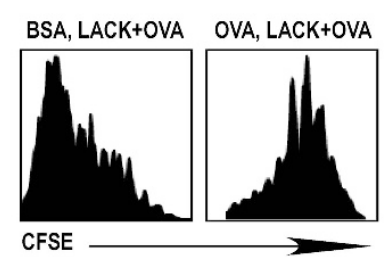

f

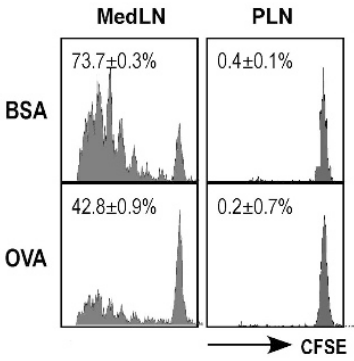

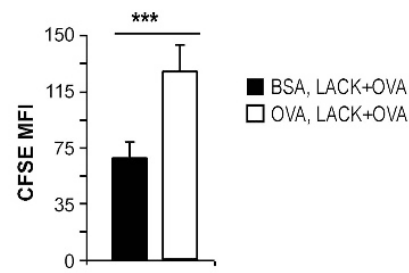

g

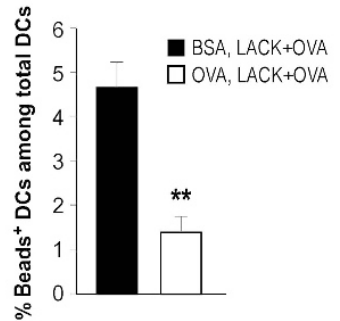

Figure 5 Airway hyperresponsiveness (AHR), airway inflammation, cytokine levels, and T-cell proliferation in ovalbumin (OVA)-tolerized mice injected with Leishmania homolog of receptors for activated c kinase (LACK)-specific Th2 cells and exposed to LACK/OVA. (a) Experimental protocol. Mice were treated with three intranasal (IN) injections of OVA or BSA, injected with $1.5 \times 10^{6}$ Carboxyfluorescein succinimidyl ester (CFSE)-labeled Thy1.1 ${ }^{+}$LACKspecific Th2 cells. Mice were injected intranasally 2 days later with LACK/OVA and analyzed 4 and 5 days later. (b) AHR. Whole body plethysmography was monitored in mice tolerized to OVA (empty circles) or BSA (filled squares, and crosses) and exposed to aerosols of LACK/OVA (full lines) or to phosphate-buffered saline (PBS) (dashed lines). Data are expressed as mean \pm s.e.m. (c) Number and phenotype of bronchoalveolar lavage fluid (BALF) cells. BALF cells were analyzed by fluorescence in situ hybridization (FACS) in the indicated groups of mice. Eosinophils, E; neutrophils, N; lymphocytes, $\mathrm{L}$; and macrophages, M. Data are expressed as mean \pm s.e.m. of three experiments with $n=6-8$ mice per group. (d) Numbers of Thy1. $1^{+}$LACK-specific Th2 cells in BALF, lung, and medLN and frequency in the blood of BSA- (filled bars) or OVA- (empty bars) tolerized mice challenged with LACK/OVA aerosols. (e) Representative plots of CFSE (left panels) and mean fluorescence intensity of CFSE (right panels) of the indicated mice. (f) In vitro antigen presentation assay. Whole-cell suspensions prepared from the MedLN and PLN of OVA- or BSA-exposed mice were incubated for 3 days with CFSElabeled LACK-specific Th2 cells. Data show representative CFSE plots for the indicated mice with the frequency of divided cells as mean \pm s.e.m. of two experiments with $n=6$ mice per group. (g) Mice underwent the same protocol as shown in (a), but also received fluorescent latex beads during LACK/ OVA challenge. Beads ${ }^{+}$CD11c ${ }^{+}$migratory DCs were analyzed by FACS in the MedLN of BSA- (filled bars) or OVA- (empty bars) tolerized mice challenged with LACK/OVA aerosols. n.s., non-significant; ${ }^{\star} P<0.05 ;{ }^{* \star} P<0.01 ;{ }^{* *} P<0.0001$.

cells from the MedLN and distal popliteal LN were purified $16 \mathrm{~h}$ after the LACK + OVA IN challenge and incubated in vitro with naïve CFSE-labeled LACK-specific WT15 CD4 ${ }^{+}$T cells to assess their ability to induce proliferation. As expected, popliteal LN cells did not promote cell division (Figure 5f). However, LACK-specific T cells proliferated more vigorously when incubated with MedLN cells from BSA-tolerized mice than MedLN cells from OVA-tolerized mice (Figure 5f).
Furthermore, to understand whether this phenomenon resulted from a quantitative (i.e., different number of LACK-loaded DCs in OVA-tolerized and BSA-tolerized mice) or qualitative defect (i.e., similar number of LACK-loaded DCs in OVA-tolerized and BSA-tolerized mice but different ability to induce T-cell proliferation), we administered PE-conjugated latex beads to OVA- and BSA-tolerized mice at the time of the challenge with LACK + OVA, and the frequency of MedLN bead ${ }^{+}$DCs was 
assessed $16 \mathrm{~h}$ later. While bead ${ }^{+}$DCs were readily detected in the MedLN of both OVA- and BSA-tolerized mice and expressed similar levels of CD80, CD86, OX40L, and MHC class II molecules (not shown), the frequency of bead ${ }^{+}$DCs was decreased from $4.7 \pm 0.7 \%$ in BSA-tolerized mice to $1.4 \pm 0.3 \%$ in OVA-tolerized animals (Figure 5g). Altogether, our data suggest that OVA-specific $\mathrm{T}_{\text {reg }}$ inhibited the proliferation of LACK-specific Th2 cells by preventing the migration of airway DCs to MedLN.

\section{DISCUSSION}

Tolerance induction protocols, in the absence of adjuvant, accompanied with the generation of $\mathrm{T}_{\text {reg }}$ cells have been reported using multiple distinct approaches. ${ }^{6,10,31-34}$ In this report, we have chosen to administer three IN injections with OVA to induce Ag-specific $\mathrm{T}_{\mathrm{reg}}$. In contrast to chronic exposure to $\mathrm{Ag}$ aerosols, ${ }^{7}$ this treatment does not confer a complete IgE unresponsiveness to further OVA sensitization and challenge (Supplementary Figure 1), suggesting that the underlying mechanisms of suppression are qualitatively and/or quantitatively different. However, the suppression induced by these series of IN injections was previously described as an effective method to prevent graft rejection ${ }^{32}$ but also as a way to suppress airway allergic inflammation. ${ }^{10}$ In the present study, we have demonstrated that OVA- $\mathrm{T}_{\text {reg }}$ generated following this approach are able to alleviate allergic symptoms induced by a different $\mathrm{Ag}$ upon their reactivation. We believe that these results represent an interesting therapeutic strategy; as such suppression would only be active upon local administration of the therapeutic Ag.

OVA-induced protection was not a result of $\mathrm{Ag}$ competition for the presentation of OVA or LACK, as non-tolerized mice challenged with both OVA and LACK displayed similar inflammatory responses as the LACK only challenged group. More importantly, experiments in which $\mathrm{CD} 4^{+} \mathrm{T}$ cells were purified from the spleen of PBS-treated, BSA- or OVAtolerized mice and injected into LACK-sensitized recipients revealed that the suppression of inflammation was mediated by $\mathrm{T}_{\text {reg }}$ that require their cognate $\mathrm{Ag}$ to be reactivated.

Inhibition studies showed that CTLA-4 was absolutely required for OVA-induced suppression of LACK-mediated allergic asthma. While we did not determine the role of CTLA-4 in our model, it has been shown to be critical for the suppressive ability of $\mathrm{T}_{\text {reg }}$ cells both in vivo and in vitro. ${ }^{35}$ CTLA-4 could prevent CD28 signaling in effector $\mathrm{T}$ cells $\left(\mathrm{T}_{\text {eff }}\right)$ by competing with CD80 and CD86, and/or to induce the synthesis of the tryptophan catabolizing enzyme indoleamine 2,3-dioxygenase by APCs, leading to T-cell suppression by both local depletion of tryptophan and induction of apoptosis via tryptophan catabolites. ${ }^{35}$ While we were unable to detect increased apoptosis of LACK-specific T cells in OVA-tolerized mice upon challenge (not shown), we cannot rule out the possibility that this phenomenon was partially responsible for OVA-induced protection.

Blocking ICOS-ICOSL interactions induced the same effect as CTLA-4 inhibition. This result supports a previous study showing that $\mathrm{ICOS}^{-1-} \mathrm{T}_{\text {reg }}$ did not confer protection upon transfer to asthmatic mice, demonstrating a crucial role of ICOS in their suppressive function. ${ }^{29}$ Taken together, these data highlight the multiple and complex role of CD25 ${ }^{+} \mathrm{T}_{\text {reg. }}$. While these cells have been proposed to act via cell contact-dependent mechanisms in vitro, many more may also take part such as inhibitory cytokine production as well as non-cytokinedependent mechanisms in vivo depending on the experimental conditions. ${ }^{36}$

Adoptive transfer of CFSE-labeled LACK-specific Th2 cells into OVA-tolerized recipient mice demonstrated that OVAspecific $\mathrm{T}_{\text {reg }}$ significantly reduced the number of LACK-specific Th2 cells in the BALF, lung, and MedLN by affecting their proliferation. Additional experiments using of fluorescently labeled latex beads revealed that OVA treatment affected the migration of airway DCs into the MedLN, suggesting that one possible suppressive mechanism of OVA- $\mathrm{T}_{\text {reg }}$ is their interaction with APCs to decrease the total load of Ag to reach the draining LNs, dampening therefore the amplitude of $\mathrm{T}_{\text {eff }}$ response. These results are in agreement with the previous findings, which reported that airway $\mathrm{T}_{\text {reg }}$ could decrease the expression of CD86 on DCs altering therefore their ability to migrate to the lung draining $\mathrm{LNs}^{37}$ While we did not characterize the state of activation of LACK-loaded DCs in our model, it is possible that OVA- $\mathrm{T}_{\text {reg }}$ are using a similar approach, supporting further the crucial role of CTLA- 4 in the protection against LACK-induced inflammation. However, it is important to notice that, while the effect on DCs could explain the decrease in proliferation of LACK-specific Th2 cells, it is also possible that OVA- $T_{\text {reg }}$ perform a second level of suppression in the MedLN by interacting directly with the $\mathrm{T}$ effector responses. Indeed, imaging data in mice have shown that $\mathrm{T}_{\text {reg }}$ interact with DCs, altering the latter and diminishing subsequent $\mathrm{DC}-\mathrm{T}_{\text {eff }}$ cell conjugate formation in vivo. ${ }^{38,39}$ In addition, Derks et al..$^{40}$ have envisioned two hypotheses of APC function in bystander suppression: a passive APC model, in which the APCs would present MHC peptide to the $T_{\text {reg, }}$ stimulating them to produce immunosuppressive cytokines that would further binds their cognate receptors on the third-party $\mathrm{T}_{\text {eff, }}$ or an active APC model, in which the APCs would propagate regulatory effects from the $\mathrm{T}_{\text {reg }}$ to the $\mathrm{T}_{\text {eff }}$ through various APC products. These two hypotheses remain to be tested in our model.

To eliminate the possibility of this protection being restricted to OVA protein, BSA-tolerized mice treated with BSA during the LACK challenge phase were equally protected from LACKinduced inflammation (data not shown). In conjunction with our findings with the human relevant allergen, ragweed, our data suggest that neither this protective phenomenon is restricted to the specific therapeutic Ag OVA, nor it is restricted to a specific allergen LACK.

Taken together, our results demonstrate that $\mathrm{T}_{\text {reg }}$ specific for a third-party therapeutic Ag could control allergic immune responses and lung inflammation when re-stimulated in vivo. Our results may explain the protective effects of SIT against allergens that are different from those used during the desensitization treatment, also primary referred to as "infectious tolerance", as reported in several epidemiological studies. ${ }^{12,13,41}$ 
In the same line of evidence, Campbell and his collaborators demonstrated the phenomenon of "linked epitope suppression" in which treatment with selected epitopes from a single allergen resulted in suppression of responses to other epitopes within the same molecule. They found that peptide treatment led to decreased proliferation and cytokine production to both treatment and non-treatment peptides. Using an experimental mouse model, they further showed that the IN administration of a single dose of peptide derived from the cat allergen Feld1 induced Ag-specific tolerance and resolution of allergic airway inflammation driven by exposure to whole cat allergen extract. While some questions remain to further understand the precise molecular and cellular mechanisms of such suppression, our study together with previous epidemiological and experimental evidence pave the way for the development of a novel curative approach that could control allergen-specific $\mathrm{Th} 2$ responses in patients with allergic asthma, and more specifically in patients sensitized to multiple allergens.

\section{METHODS}

Mice. Six-week-old BALB/c mice were purchased from The Centre d'Elevage Janvier (France) and housed under standard pathogen free conditions. LACK TCR transgenic mice (WT15 RAG-1 KO) on the $\mathrm{BALB} / \mathrm{c}$ background as previously described ${ }^{42}$ were bred in our animal facility at the Institut de Pharmacologie Moleculaire et Cellulaire (Valbonne, France). In this study, WT15 transgenic mice were further crossed onto RAG-1 ${ }^{-1-}$ Thy $1.1^{+/+} \mathrm{BALB} / \mathrm{c}$ mice. All experimental protocols were approved by the local animal ethic committee.

Reagents. LACK recombinant protein was produced in E. coli, purified as described previously, ${ }^{43}$ and detoxified using an Endotrap column (Profos, Bernried am Starnberger See, Germany). Lipopolysaccharide contents in LACK protein were below $5 \mathrm{ng} \mathrm{mg}^{-1}$ as determined using Limulus Amoebocyte Lysate (LAL) assay (Pierce, Illkirch, France). LACK $_{156-173}$ peptide was purchased from Mimotopes (Clayton, Victoria, Australia). T1/ST2 mAbs were purchased from MD Biosciences (St Paul, MN). Monoclonal antibodies to CD3, CD4, CD25, Thy1.1, CD11c, IA/IE, CD80, CD86, IL-4, and IL-5 were purchased from BD Biosciences (Le Pont de Claix, France).

Induction of allergic asthma and tolerization to OVA. Sensitization was performed by two intraperitoneal injections of $10 \mu \mathrm{g}$ of LACK in $2 \mathrm{mg}$ of Aluminium hydroxide (Alum) (Pierce) at days 0 and 7. On days 12,13 , and 14 , mice were tolerized to OVA by injecting IN $100 \mu \mathrm{g}$ of LPS-free OVA (Profos) as described previously. ${ }^{8}$ From day 23 to day 27 , mice were exposed either to LACK $(0.15 \%)$ or to LACK plus OVA $(0.2 \%)$ aerosols (administered $8 \mathrm{~h}$ apart) for $20 \mathrm{~min}$ using an ultrasonic nebulizer (Ultramed, Medicalia, Le Tholonet, France). Mice were analyzed on days 28 and 29 for AHR and airway inflammation, respectively. When indicated, mice were injected with either $0.5 \mathrm{mg}$ of anti-CTLA-4 mAb (9H10) anti-ICOS (17G9) or isotype control (IgG1, GL113) every other day over the challenge period starting 1 day before the first aerosol. For ragweed-induced asthma, mice were first tolerized to OVA by receiving IN injections of OVA on days 0,1 , and 2 and further sensitized to ragweed via IN administrations of $25 \mu \mathrm{g}$ ragweed (Greer Laboratories, Lenoir, NC) on days 11, 15, 19, and 23. Mice received a last challenge of ragweed on day 27 or ragweed and OVA on days 26 and 27. Mice were analyzed on day 28 for AHR and on day 29 for airway inflammation.

Th2 cell transfers. In some experiments, mice were first tolerized to OVA, BSA, or PBS and injected i.v on day 11 with LACK-specific $\mathrm{CD} 4{ }^{+} \mathrm{Th} 2$ cells. Mice were challenged $24 \mathrm{~h}$ later with a single IN injection of LACK $(30 \mu \mathrm{g})$ and OVA $(100 \mu \mathrm{g})$, and assessed for AHR, and immunological parameters 3 and 4 days later, respectively.

Airway hyperresponsiveness. For non-invasive measurements, mice were analyzed 1 day after the last aerosol challenge using whole body plethysmography as described previously. ${ }^{44}$ Invasive measurements of dynamic lung resistance and compliance were performed 1 day after the last aerosol challenge using a Flexivent apparatus (SCIREQ, Emka Technologies, Paris, France) as previously described. ${ }^{25}$ Briefly, mice were anesthetized $\left(5 \mathrm{ml} \mathrm{kg}^{-1}\right.$ Dormitor $10 \%$ (Medetomidine, Pfizer, Paris, France)-Imalgene 10\% (Ketamine, Merial, Lyon, France) tracheotomized, paralyzed $\left(5 \mathrm{ml} \mathrm{kg}^{-1}\right.$ Pavulon $1 \%$ (Pancuronium bromide, Organon, Fresnes, France) and immediately intubated with an 18$\mathrm{G}$ catheter, followed by mechanical ventilation. Respiratory frequency was set at 150 breaths per minute with a tidal volume of $0.2 \mathrm{ml}$, and a positive-end expiratory pressure of $2 \mathrm{ml} \mathrm{H}_{2} \mathrm{O}$ was applied. Increasing concentrations of methacholine $\left(0-24 \mathrm{mg} \mathrm{ml}^{-1}\right)$ were administered at the rate of 20 puffs per $10 \mathrm{~s}$, with each puff of aerosol delivery lasting $10 \mathrm{~ms}$, via a nebulizer aerosol system with a $2.5-4 \mu \mathrm{m}$ aerosol particle size generated by a nebulizer head (Aeroneb, Aerogen, Galway, France). Baseline resistance was restored before administering the subsequent doses of methacholine.

Analysis of BALF cells. Mice were bled and a canula was inserted into the trachea. Lungs were washed three times with $1 \mathrm{ml}$ of warmed PBS. For differential BALF cell counts, cells were stained with $\mathrm{mAb}$ antiCCR3 (R\&D, Lille, France), anti-Gr1, anti-CD3, and anti-CD19 mAbs (Becton Dickinson, Le Pont de Claix, France) and analyzed by fluorescence in situ hybridization (FACS) using a FACScalibur flow cytometer (BD Bioscience) and Cellquest software (BD Bioscience). Eosinophils were defined as CCR3 ${ }^{+} \mathrm{CD}^{-} \mathrm{CD}^{-} 9^{-}$, neutrophils as Gr- $1^{\text {high }} \mathrm{CD} 3^{-} \mathrm{CD} 19^{-}$, lymphocytes as $\mathrm{CD} 3^{+} \mathrm{CD} 19^{+}$, and alveolar macrophages as large autofluorescent cells.

Serum antibody measurements. Serum LACK-specific IgG1 and IgE were measured by ELISA. For IgG1 quantification, Ag-coated Maxisorp plates (Nunc, Illkirch, France) were incubated with serial dilution of sera and biotinylated anti-IgG1 mAb (BD). For Ag-specific IgE, plates were first coated with the respective capture mAb (BD), and incubated with serum dilutions. Biotinylated-LACK Ag was then added. HRP-conjugated streptavidin (BD) and TMB (KPL, Gaithersburg, $\mathrm{MD}$ ) were used for detection.

Tissue processing. Lungs, LN, or spleens were cut into small pieces in HBSS containing $400 \mathrm{U}$ type I collagenase and $1 \mathrm{mg} \mathrm{ml}^{-1}$ DNAse I and digested for $30 \mathrm{~min}$ at $37^{\circ} \mathrm{C}$. Cells were strained through a $70-\mu \mathrm{m}$ cell strainer. Erythrocytes were lysed with ACK lysis buffer.

Cytokine assays. Lung samples were homogenized in $\mathrm{C}^{2+}$ - and $\mathrm{Mg}^{2+}$-free HBSS. BAL and lung supernatants were used. Multiplex IL4, IL-5, IL-13, and IFN- $\gamma$ analysis was performed with CBA using FACS array (BD Biosciences). For intracellular staining, cells were incubated with $100 \mu \mathrm{g} \mathrm{ml}^{-1} \mathrm{LACK}$ and $1 \mu \mathrm{g} \mathrm{ml}^{-1}$ of anti-CD28 (BD) for $6 \mathrm{~h}$. Brefeldin A $\left(5 \mu \mathrm{g} \mathrm{ml}^{-1}\right.$, Sigma, Saint Quentin Fallavier, France) was added during the last $4 \mathrm{~h}$. Cells were then stained with anti-CD4 mAb, fixed, permeabilized using cytofix/cytoperm reagent (BD), stained with anti-IL-4, or IL-5 (BD) and analyzed by FACS.

$\mathrm{CD}^{+}$T-cell transfer. Donor mice were tolerized to OVA, BSA, or PBS as described above. Cells were prepared from spleens 21 days later, and $\mathrm{CD} 4{ }^{+} \mathrm{T}$ cells were enriched by negative depletion using CD4 isolation kit (Dynal, Illkirch, France) and further sorted using a highspeed sorter VANTAGE SETLO ${ }^{+}$flow cytometer (BD) after staining with anti-CD3 and anti-CD4 mAbs. CD4 purity was $>95 \%$. In some experiments, enriched $\mathrm{CD} 4{ }^{+} \mathrm{T}$ cells were stained with antibodies to $\mathrm{CD} 25, \mathrm{CD} 4$, and $\mathrm{CD} 3$, and $\mathrm{CD} 25^{-}$and $\mathrm{CD} 25^{+} \mathrm{CD} 4^{+} \mathrm{T}$-cell populations were sorted by FACS. Sorted cells were then injected i.v. into sensitized mice $\left(4 \times 10^{6}\right.$ or $1.5 \times 10^{6}$ cells per mouse, respectively) as described previously. ${ }^{26,27}$ 
Statistic analysis. ANOVA for repeated measures was used to determine the levels of difference between groups of mice for plethysmography measurements. Comparisons for all pairs were performed by Mann-Whitney $U$ test. Significance levels were set at a $P$ value of 0.05 .

SUPPLEMENTARY MATERIAL is linked to the online version of the paper at http://www.nature.com/mi

\section{ACKNOWLEDGMENTS}

We thank Nicolas Guy and the animal facility staff for their excellent animal care, as well as Julie Cazareth for the cell sorting experiments. This work was supported by a grant from the Fondation pour la Recherche Médicale and INSERM. S.N. was supported by a fellowship from the FRM, A.L. was supported by a fellowship from Vaincre la Mucoviscidose, and A.K is supported by a grant from the Agence Nationale de la Recherche (ANR).

\section{DISCLOSURE}

The authors declared no conflict of interest.

(c) 2015 Society for Mucosal Immunology

\section{REFERENCES}

1. Casale, T.B. \& Stokes, J.R. Immunotherapy: what lies beyond. J. Allergy Clin. Immunol. 133, 612-619. quiz 620 (2014).

2. Akdis, C.A. et al. Epitope-specific T cell tolerance to phospholipase A2 in bee venom immunotherapy and recovery by IL-2 and IL-15 in vitro. J. Clin. Invest. 98, 1676-1683 (1996).

3. Akdis, C.A., Blesken, T., Wymann, D., Akdis, M. \& Blaser, K. Differential regulation of human Tcell cytokine patterns and lgE and lgG4 responses by conformational antigen variants. Eur. J. Immunol. 28, 914-925 (1998).

4. Jutel, M. et al. IL-10 and TGF-beta cooperate in the regulatory T cell response to mucosal allergens in normal immunity and specific immunotherapy. Eur. J. Immunol. 33, 1205-1214 (2003).

5. Francis, J.N., Till, S.J. \& Durham, S.R. Induction of IL-10 + CD4 + CD25+ $\mathrm{T}$ cells by grass pollen immunotherapy. J. Allergy Clin. Immunol. 111, 1255-1261 (2003).

6. Ostroukhova, M. et al. Tolerance induced by inhaled antigen involves CD4(+) T cells expressing membrane-bound TGF-beta and FOXP3. J. Clin. Invest. 114, 28-38 (2004).

7. Seymour, B.W.P., Gershwin, L.J. \& Coffman, R.L. Aerosol-induced immunoglobulin (Ig)-Eunresponsiveness to ovalbumin does not require CD8(+) or T cell receptor (TCR)-gamma/delta( + ) T cells or interferon (IFN)-gamma in a murine model of allergen sensitization. J. Exp. Med. 187, 721-731 (1998).

8. Akbari, O., Dekruyff, R.H. \& Umetsu, D.T. Pulmonary dendritic cells producing IL-10 mediate tolerance induced by respiratory exposure to antigen. Nat. Immunol. 2, 725-731 (2001).

9. Akbari, O. et al. Antigen-specific regulatory T cells develop via the ICOSICOS-ligand pathway and inhibit allergen-induced airway hyperreactivity. Nat. Med. 8, 1024-1032 (2002).

10. Stock, P., Akbari, O., DeKruyff, R.H. \& Umetsu, D.T. Respiratory tolerance is inhibited by the administration of corticosteroids. J. Immunol. $\mathbf{1 7 5}$, 7380-7387 (2005).

11. Chen, W. et al. Conversion of peripheral CD4 +CD25- naive $T$ cells to CD $4+\mathrm{CD} 25+$ regulatory T cells by TGF-beta induction of transcription factor Foxp3. J. Exp. Med. 198, 1875-1886 (2003).

12. Des Roches, A. et al. Immunotherapy with a standardized Dermatophagoides pteronyssinus extract. VI. Specific immunotherapy prevents the onset of new sensitizations in children. J. Allergy Clin. Immunol. 99, 450-453 (1997).

13. Pajno, G.B., Barberio, G., De Luca, F., Morabito, L. \& Parmiani, S. Prevention of new sensitizations in asthmatic children monosensitized to house dust mite by specific immunotherapy. A six-year follow-up study. Clin. Exp. Allergy 31, 1392-1397 (2001).

14. Bullock, W.W., Katz, D.H. \& Benacerraf, B. Induction of T-lymphocyte responses to a small molecular weight antigen. II. specific tolerance induced in azebenzenearsonate (ABA)-specific T cells in Guniea pigs by administration of low doses of an ABA conjugate of chloroacetyl tyrosine in incomplete Freund's adjuvant. J. Exp. Med. 142, 261-274 (1975).
15. Smith, C.E. \& Miller, S.D. Multi-peptide coupled-cell tolerance ameliorates ongoing relapsing EAE associated with multiple pathogenic autoreactivities. J. Autoimmun. 27, 218-231 (2006).

16. Turley, D.M. \& Miller, S.D. Peripheral tolerance induction using ethylenecarbodiimide-fixed APCs uses both direct and indirect mechanisms of antigen presentation for prevention of experimental autoimmune encephalomyelitis. J. Immunol. 178, 2212-2220 (2007).

17. Kendal, A.R. \& Waldmann, H. Infectious tolerance: therapeutic potential. Curr. Opin. Immunol. 22, 560-565 (2010).

18. Qin, S. et al. "Infectious" transplantation tolerance. Science 259, 974-976 (1993).

19. Miller, A., Hafler, D.A.\& Weiner, H.L. Tolerance and suppressor mechanisms in experimental autoimmune encephalomyelitis: implications for immunotherapy of human autoimmune diseases. FASEB J. 5, 2560-2566 (1991).

20. Miller, A., Lider, O., al-Sabbagh, A. \& Weiner, H.L. Suppression of experimental autoimmune encephalomyelitis by oral administration of myelin basic protein. $V$. Hierarchy of suppression by myelin basic protein from different species. J. Neuroimmunol. 39, 243-250 (1992).

21. Homann, D. et al. Autoreactive CD4 + T cells protect from autoimmune diabetes via bystander suppression using the IL-4/Stat6 pathway. Immunity 11, 463-472 (1999).

22. al-Sabbagh, A., Miller, A., Santos, L.M. \& Weiner, H.L. Antigen-driven tissue-specific suppression following oral tolerance: orally administered myelin basic protein suppresses proteolipid protein-induced experimental autoimmune encephalomyelitis in the SJL mouse. Eur. J. Immunol. 24, 2104-2109 (1994).

23. Aharoni, R., Teitelbaum, D., Sela, M. \& Arnon, R. Copolymer 1 induces T cells of the Thelper type 2 that crossreact with myelin basic protein and suppress experimental autoimmune encephalomyelitis. Proc. Natl. Acad. Sci. USA 94, 10821-10826 (1997).

24. Miska, J. et al. Real-time immune cell interactions in target tissue during autoimmune-induced damage and graft tolerance. J. Exp. Med. 211, 441-456 (2014).

25. Mionnet, C. et al. CX3CR1 is required for airway inflammation by promoting T helper cell survival and maintenance in inflamed lung. Nat. Med. 16, 1305-1312 (2010).

26. Navarro, S. et al. The oral administration of bacterial extracts prevents asthma via the recruitment of regulatory T cells to the airways. Mucosal Immunol. 4, 53-65 (2011).

27. Verhasselt, $V$. et al. Breast milk-mediated transfer of an antigen induces tolerance and protection from allergic asthma. Nat. Med. 14, 170-175 (2008).

28. Yamaguchi, T., Wing, J.B. \& Sakaguchi, S. Two modes of immune suppression by Foxp3 $(+)$ regulatory T cells under inflammatory or noninflammatory conditions. Semin. Immunol. 23, 424-430 (2011).

29. Busse, M., Krech, M., Meyer-Bahlburg, A., Hennig, C. \& Hansen, G. ICOS mediates the generation and function of CD4 + CD25 + Foxp3 + regulatory Tcells conveying respiratory tolerance. J. Immunol. 189, 1975-1982 (2012).

30. Cohn, L., Homer, R.J., Marinov, A., Rankin, J. \& Bottomly, K. Induction of airway mucus production By Thelper 2 (Th2) cells: a critical role for interleukin 4 in cell recruitment but not mucus production. J. Exp. Med. 186, 1737-1747 (1997).

31. Mahnke, K., Qian, Y., Knop, J. \& Enk, A.H. Induction of CD4 + /CD25 + regulatory Tcells by targeting of antigens to immature dendritic cells. Blood 101, 4862-4869 (2003).

32. Chai, J.G., James, E., Dewchand, H., Simpson, E. \& Scott, D. Transplantation tolerance induced by intranasal administration of $\mathrm{HY}$ peptides. Blood 103, 3951-3959 (2004)

33. Apostolou, I. \& von Boehmer, H. In vivo instruction of suppressor commitment in naive T cells. J. Exp. Med. 199, 1401-1408 (2004).

34. Campbell, J.D. et al. Peptide immunotherapy in allergic asthma generates IL-10-dependent immunological tolerance associated with linked epitope suppression. J. Exp. Med. 206, 1535-1547 (2009).

35. Wing, K., Yamaguchi, T. \& Sakaguchi, S. Cell-autonomous and -nonautonomous roles of CTLA-4 in immune regulation. Trends Immunol. 32, 428-433 (2011).

36. Shevach, E.M. CD4 + CD25 + suppressor T cells: more questions than answers. Nat. Rev. Immunol. 2, 389-400 (2002).

37. Strickland, D.H. et al. Boosting aimay T-regulatory cells by gastrointestinal stimulation as a strategy for asthma control. Mucosal Immunol. 4, 43-52 (2010).

38. Tang, Q. \& Krummel, M.F. Imaging the function of regulatory T cells in vivo. Curr. Opin. Immunol. 18, 496-502 (2006). 
39. Tadokoro, C.E. et al. Regulatory T cells inhibit stable contacts between CD4 + Tcells and dendritic cells in vivo. J. Exp. Med. 203, 505-511 (2006).

40. Derks, R.A., Jankowska-Gan, E., Xu, Q. \& Burlingham, W.J. Dendritic cell type determines the mechanism of bystander suppression by adaptive Tregulatory cells specific for the minor antigen HA-1. J. Immunol. 179, 3443-3451 (2007).

41. Inal, A. et al. Prevention of new sensitizations by specific immunotherapy in children with rhinitis and/or asthma monosensitized to house dust mite. J. Investig. Allergol. Clin. Immunol. 17, 85-91 (2007).
42. Wang, Q. et al. CD4 promotes breadth in the TCR repertoire. J. Immunol. 167, 4311-4320 (2001).

43. Mougneau, E. et al. A Leishmania protective T-cell antigen identified using a new expression cloning strategy. Vaccines 95 : (CSH, eds) 51-56 (1995).

44. Hamelmann, E. et al. Noninvasive measurement of airway responsiveness in allergic mice using barometric plethysmography. Am. J. Respir. Crit. Care Med. 156, 766-775 (1997). 